\title{
Vitamin $C$ and fibre consumption from fruits and vegetables improves oxidative stress markers in healthy young adults
}

\author{
Helen Hermana M. Hermsdorff ${ }^{1}$, Kiriaque B. F. Barbosa ${ }^{2}$, Ana Carolina P. Volp ${ }^{3}$, Blanca Puchau ${ }^{1}$, \\ Josefina Bressan $^{4}$, M. Ángeles Zulet ${ }^{1}$ and J. Alfredo Martínez ${ }^{1 *}$ \\ ${ }^{1}$ Department of Nutrition, Food Science, Physiology and Toxicology, University of Navarra, C/Irunlarrea 1, 31008 \\ Pamplona, Spain \\ ${ }^{2}$ Nutrition Center, Federal University of Sergipe, Aracaju, Brazil \\ ${ }^{3}$ Department of Clinical and Social Nutrition, Federal University of Ouro Preto, Ouro Preto, Brazil \\ ${ }^{4}$ Department of Nutrition and Health, Federal University of Viçosa, Viçosa, Brazil
}

(Submitted 18 March 2011 - Final revision received 4 July 2011 - Accepted 6 July 2011 - First published online 7 September 2011)

\section{Abstract}

The aim of the present cross-sectional study was to assess the potential relationships between fruit and vegetable (FV) consumption and some oxidative stress markers in young adults, with particular emphasis on fibre and vitamin $\mathrm{C}$ intake. The study enrolled 246 healthy subjects (eighty-eight men and 158 women), with a mean age of 22 (SD 3) years and a mean BMI of $21.9(\mathrm{sD} 2.8) \mathrm{kg} / \mathrm{m}^{2} . \mathrm{Dietary}$ intake, anthropometry, blood pressure, lifestyle features and blood biochemical data were assessed with validated procedures. Those subjects in the highest tertile (T) of FV consumption $(\geq 705 \mathrm{~g} / \mathrm{d}$ ) had statistically lower oxidised LDL (ox-LDL) concentrations as well as higher plasma total antioxidant capacity (TAC) and glutathione peroxidase (GPx) activity ( $P$ for trend $<0 \cdot 05)$, after adjusting for sex, age, energy intake, physical activity, smoking, BMI, vitamin supplement use and other confounding factors. Moreover, plasma ox-LDL concentrations showed a decreasing trend and TAC an increasing trend across tertiles of fibre (T3: $\geq 14 \mathrm{~g} / \mathrm{d}$ ) and vitamin C (T3: $\geq 150 \mathrm{mg} / \mathrm{d}) \mathrm{from} \mathrm{FV} \mathrm{intake,} \mathrm{while}$ GPx activity was positively associated with vitamin $\mathrm{C}$ intake $(P$ for trend $<0.05)$. In conclusion, greater FV consumption was independently associated with reduced ox-LDL as well as increased TAC and GPx activity in healthy young adults, with dietary fibre and vitamin C from FV clearly being implicated in this beneficial relationship.

\section{Key words: Fruits: Vegetables: Glutathione peroxidase: Oxidised LDL: Antioxidants}

Oxidative stress impairment or altered antioxidant status plays a pivotal role in the onset of certain chronic diseases such as the metabolic syndrome, type 2 diabetes and $\mathrm{CVD}^{(1-3)}$. In this sense, glutathione peroxidase (GPx) is a recognised antioxidant enzyme, which prevents and controls $\mathrm{H}_{2} \mathrm{O}_{2}$ accumulation and free radical species production for the maintenance of cellular redox homeostasis ${ }^{(4)}$. Furthermore, GPx activity has been reported as reduced in hypertensive and high-cardiovascular-risk subjects ${ }^{(5,6)}$. In turn, although controversy exists surrounding the extrapolation of plasma total antioxidant capacity (TAC) data as a measure of capacity to suppress molecular oxidation ${ }^{(7,8)}$, TAC has been repeatedly assessed in order to determine the combined actions of all antioxidants in samples. Thus, lower TAC in obese and hypertensive subjects as well as in subjects suffering from the metabolic syndrome and CVD features, when compared with healthy controls, have been reported in different studies $^{(3,9-11)}$. In addition, oxidised LDL (ox-LDL), an important oxidative stress marker, are taken up by scavenger receptors on macrophages and contribute to pro-inflammatory processes, with an activation of a redox-sensitive transcriptional factor (NF-кB) as well as the secretion of specific cytokines and adhesion molecules ${ }^{(12)}$. Moreover, increased circulating ox-LDL has been associated with central obesity ${ }^{(13)}$, metabolic syndrome manifestation ${ }^{(1)}$ and subclinical atherosclerosis $^{(2)}$.

In contrast, a high consumption of fruits and vegetables (FV) has been inversely linked with metabolic syndrome features ${ }^{(14)}, \mathrm{CVD}^{(15)}$ and total mortality ${ }^{(16)}$. In fact, FV contain vitamins, carotenoids, polyphenols and other bioactive compounds, which make them a food group with a high dietary antioxidant capacity and multiple anti-inflammatory actions ${ }^{(17,18)}$.

Overall, the present study assessed the potential association between FV consumption and plasma concentrations of

Abbreviations: FV, fruit and vegetable; GPx, glutathione peroxidase; HOMA-IR, homeostasis model assessment of insulin resistance; MET, metabolic equivalent; ox-LDL, oxidised LDL; TAC, total antioxidant capacity.

*Corresponding author: Dr J. A. Martínez, fax +34 948425649, email jalfmtz@unav.es 
Ox-LDL, TAC as well as GPx activity in erythrocytes, in young healthy adults. Special attention was given to the putative involvement of fibre and vitamin $\mathrm{C}$ intake.

\section{Subjects and methods}

\section{Subjects}

Participants of the present study were involved in a study of Interuniversity Cooperation between the Federal University of Viçosa (Viçosa, Brazil, CAPES/MECD-DGU 109/06) and the University of Navarra (Pamplona, Spain, PHB-2005-0119PC). Thus, a group of 246 subjects from Brazil (sixty-one men and seventy-six women) and Spain (twenty-seven men and eighty-two women), with a mean age of 22 (SD 3) years (range $18-35$ years old) and a mean BMI of 21.9 (SD $2 \cdot 8) \mathrm{kg} / \mathrm{m}^{2}$ (range $18.5-34.9 \mathrm{~kg} / \mathrm{m}^{2}$ ), were enrolled in the present study.

The volunteers were recruited through magazines, radio, web pages and Intranet tools from both universities. In the enrolment message, the age range (18-35 years old) was mentioned as well as relevant information for those interested in participating in the present cross-sectional nutritional study. Exclusion criteria included inflammatory, heart and respiratory diseases, hormonal treatments, or prescribed drugs that affect glucose and lipid metabolism, alcohol and drug dependence, recent involvement in diets designed to elicit weight loss, or unstable body weight within the previous 3 months. The study was conducted according to the guidelines laid down in the Declaration of Helsinki and all procedures involving human subjects were approved by the Ethics Committee in Human Research of the Federal University of Viçosa (reference no. 009/2006) and by the Investigation Ethics Committee of the Clínica Universidad de Navarra (reference no. 79/2005). Written informed consent was obtained from all subjects.

\section{Dietary intake assessment}

Diet records were analysed using country-specific databases. In the Brazilian sample, dietary intake information was obtained by $3 \mathrm{~d}$ record. Daily food consumption was estimated as portion size for each consumed food item, taking into consideration both preparation (raw or cooked) and edible portion. Nutrient intake was estimated using Diet Pro $5 \mathrm{i}{ }^{\circledR}$ software (AS Sistemas, Viçosa, Brazil), adapted for the latest available information in the food composition tables for $\operatorname{Brazil}^{(19,20)}$. In the Spanish sample, dietary intake information was obtained by a semi-quantitative FFQ with 136 food items, which is validated for Spanish people ${ }^{(21)}$. Daily food consumption was estimated as frequency $\times$ portion size for each consumed food item. Nutrient intake was estimated using a computer program specifically designed for this purpose and the latest available information included in the food composition tables for Spain ${ }^{(22,23)}$.

Thus, FV consumption included thirteen fruit items, such as orange/tangerine, banana, apple/pear, strawberry, grapefruit, peach/apricot/nectarine, watermelon, melon, mango, papaya, avocado, kiwi and other fruits (cherry, plum, guava, fig and pineapple), and ten vegetables items, such as spinach/dark-green leaves, lettuce/chicory, cauliflower/broccoli, cabbage, tomatoes, carrot/pumpkin, green beans, peppers, aubergines/zucchini/cucumber and other vegetables (asparagus, beetroot, 'gazpacho' and onion). Natural fruit juices (100\% fruit) were also counted separately.

Furthermore, we evaluated the occurrence of under- or over-reporting in the present study sample, examining the ratio between reported energy intake and energy expenditure requirements. The energy expenditure requirements were calculated by means of the Dietary Reference Intake prediction equations ${ }^{(24)}$, derived from large pooled datasets compiled from doubly labelled water studies. We chose this ratio because it is more stringent than the Goldberg method (reported energy intake:BMR) in a sample with different physical activity levels ${ }^{(25)}$. Thus, those subjects with energy intake:energy expenditure requirements $2 \mathrm{SD}(0.7)$ or more below or above the mean value from the sample (1.17) were identified as under- $(<0.47)$ and over-reporters $(>1.87)$, respectively. Given that the statistical analyses were not changed with the exclusion of volunteers (data not shown), we maintained all the participants in the results (Table 1).

\section{Clinical and biochemical assessments}

Anthropometric determinations were taken using standard measurement procedures in accordance with previously described protocols ${ }^{(26,27)}$, as agreed by both the universities participating in the study. Thus, BMI was calculated as the ratio between weight $(\mathrm{kg})$ and the squared height $\left(\mathrm{m}^{2}\right)$, which was applied to categorise normal-weight (18.5$24.9 \mathrm{~kg} / \mathrm{m}^{2}$ ), overweight $\left(25-29.9 \mathrm{~kg} / \mathrm{m}^{2}\right)$ and obese (BMI $\geq 30 \mathrm{~kg} / \mathrm{m}^{2}$ ) subjects, according to the WHO criteria ${ }^{(28)}$. Systolic and diastolic blood pressures were measured twice following the WHO standards ${ }^{(29)}$.

Venous blood samples were drawn by venepuncture after a $12 \mathrm{~h}$ overnight fast. The EDTA plasma and serum samples were separated from whole blood by centrifugation $(2205 \boldsymbol{g}$ for $15 \mathrm{~min}$ at $4^{\circ} \mathrm{C}$ ), and were frozen immediately at $-80^{\circ} \mathrm{C}$ until assay. Serum concentrations of TAG, total cholesterol, HDL-cholesterol, glucose and insulin were measured by standardised assessment methods as described previously ${ }^{(26,30)}$. Serum LDL-cholesterol and insulin resistance as homeostasis model assessment of insulin resistance (HOMA-IR) were calculated using the Friedewald et $a l^{(31)}$ and Matthews et al. ${ }^{(32)}$ equations, respectively. Plasma ox-LDL was measured using ELISA kits from Mercodia (Uppsala, Sweden), based on the mouse monoclonal antibody $4 \mathrm{E} 6$, which is directed against a conformational epitope in oxidised apoB-100 ${ }^{(33,34)}$. Plasma TAC was determined using a commercial colorimetric kit (Cayman Chemical Corporation, Ann Arbor, MI, USA), based on the inhibition of the oxidation of $\operatorname{ABTS}^{\circledR}(2,2$-azino-di-[3ethylbenzthiazoline sulphonate]) to $\operatorname{ABTS}^{\circledR \cdot+}(35,36)$, which is subsequently quantified as mmol Trolox equivalents. Finally, GPx activity was measured in erythrocytes by using a commercially available kit (Cayman Chemical Corporation), based on the rate of the oxidation of NADPH to NADP ${ }^{+(37)}$. 
Table 1. Anthropometric, clinical and lifestyle characteristics, according to tertiles $(T)$ of energy-adjusted fruit and vegetable consumption

(Mean values with their standard errors, number of participants and percentages, $n$ 246)

\begin{tabular}{|c|c|c|c|c|c|c|c|}
\hline & \multicolumn{6}{|c|}{ Energy-adjusted fruit and vegetable consumption $(\mathrm{g} / \mathrm{d})$} & \multirow[b]{3}{*}{$P^{*}$} \\
\hline & \multicolumn{2}{|c|}{$\mathrm{T} 1(<210)$} & \multicolumn{2}{|c|}{ T2 (210-705) } & \multicolumn{2}{|c|}{ T3 $(\geq 705)$} & \\
\hline & Mean & SE & Mean & SE & Mean & SE & \\
\hline Participants $(n)$ & \multicolumn{2}{|c|}{82} & \multicolumn{2}{|c|}{82} & \multicolumn{2}{|c|}{82} & \\
\hline Age (years) & 22 & 0.3 & 22 & 0.3 & 22 & 0.3 & $0 \cdot 100$ \\
\hline Women (\%) & \multicolumn{2}{|c|}{53.8} & \multicolumn{2}{|c|}{$59 \cdot 3$} & \multicolumn{2}{|c|}{$70 \cdot 2$} & $<0.001$ \\
\hline BMI $\left(\mathrm{kg} / \mathrm{m}^{2}\right)$ & $22 \cdot 0$ & 0.3 & $22 \cdot 0$ & 0.3 & $21 \cdot 8$ & 0.3 & 0.946 \\
\hline Waist circumference $(\mathrm{cm})$ & $76 \cdot 8$ & 0.9 & 74.9 & 0.8 & $72 \cdot 3$ & 0.9 & 0.005 \\
\hline $\mathrm{SBP}(\mathrm{mmHg})$ & 112 & 1.0 & 113 & 1.1 & 111 & 1.1 & 0.451 \\
\hline $\mathrm{DBP}(\mathrm{mmHg})$ & $73 \dagger$ & 0.8 & 69 & 0.8 & 66 & 0.8 & $<0.001$ \\
\hline Glucose (mg/l) & $902 \dagger$ & 7 & 875 & 8 & 849 & 8 & $<0.001$ \\
\hline Insulin (pmol/l) & $68 \cdot 1$ & 3.5 & $64 \cdot 6$ & $2 \cdot 8$ & 63.9 & 2.8 & 0.155 \\
\hline HOMA-IR & $2 \cdot 2 \dagger$ & $0 \cdot 10$ & $2 \cdot 0$ & 0.09 & 1.8 & 0.08 & 0.039 \\
\hline Total cholesterol (mg/l) & 1610 & 36 & 1690 & 27 & 1690 & 30 & 0.237 \\
\hline HDL-C (mg/l) & $480 \dagger$ & 15 & 540 & 14 & 570 & 13 & 0.001 \\
\hline LDL-C (mg/l) & 900 & 30 & 960 & 25 & 970 & 25 & 0.753 \\
\hline TAG (mg/l) & $890 \dagger$ & 52 & 820 & 32 & 630 & 31 & 0.009 \\
\hline PA practice (\%) & \multicolumn{2}{|c|}{$55 \cdot 6$} & \multicolumn{2}{|c|}{$56 \cdot 8$} & \multicolumn{2}{|c|}{62.5} & 0.481 \\
\hline MET (h/week) & $45 \dagger$ & $5 \cdot 6$ & 49 & $10 \cdot 2$ & $60 \cdot 3$ & 11.5 & 0.008 \\
\hline Smoking status & & & & & & & 0.229 \\
\hline Never (\%) & \multicolumn{2}{|c|}{75} & \multicolumn{2}{|c|}{74} & \multicolumn{2}{|c|}{$85 \cdot 2$} & \\
\hline Former (\%) & \multicolumn{2}{|c|}{7.5} & \multicolumn{2}{|c|}{10} & \multicolumn{2}{|c|}{4.9} & \\
\hline Current (\%) & \multicolumn{2}{|c|}{$17 \cdot 5$} & \multicolumn{2}{|c|}{16} & \multicolumn{2}{|c|}{9.9} & \\
\hline Vitamin supplement use (\%) & \multirow{2}{*}{\multicolumn{2}{|c|}{$\begin{array}{l}7.5 \\
2.5\end{array}$}} & \multirow{2}{*}{\multicolumn{2}{|c|}{$\begin{array}{c}14.8 \\
2.5\end{array}$}} & \multirow{2}{*}{\multicolumn{2}{|c|}{$\begin{array}{c}18.5 \\
7.7\end{array}$}} & 0.004 \\
\hline Over-reporters (\%) & & & & & & & 0.107 \\
\hline
\end{tabular}

SBP, systolic blood pressure; DBP, diastolic blood pressure; HOMA-IR, homeostasis model assessment of insulin resistance; HDL-C, HDL-cholesterol; LDL-C, LDL-cholesterol; PA, physical activity; MET, metabolic equivalent index.

* $P$ value from one-factor ANOVA test or $\chi^{2}$ test, for continuous or categorical variables, respectively. Non-normally distributed variables were log-transformed before analysis.

† Mean values were significantly different for T1 from those of T3 $(P<0.05$; post hoc Bonferroni test)

\section{Assessment of other variables}

For lifestyle variables, participants were asked about their smoking status (never, former or current smokers) and vitamin supplement use (yes/no). With respect to physical activity, participants reported whether they took regular physical activity (yes/no), and if so, the type and the volume of activity (h/week). To quantify the volume of activity, a metabolic equivalent (MET) index was also computed by assigning a multiple of RMR (MET score) to each activity ${ }^{(38)}$. The sum of all activities to give a weekly MET/h was calculated as described elsewhere ${ }^{(39)}$.

\section{Statistical analysis}

Normal distribution of the data was determined by the Shapiro-Wilk test. Non-normally distributed variables were log-transformed before statistical analyses. Comparisons between the three groups were performed by one-factor ANOVA tests, while the post hoc Bonferroni test was used for multiple comparisons. Dietary intakes were adjusted for daily energy intake by the residual method, applying separate models for women and men ${ }^{(40)}$. To assess the associations between FV consumption and oxidative stress markers, we categorised the participants by tertiles of this food-group consumption. Linear trends were assessed by assigning the median value to each tertile of $\mathrm{FV}$ consumption and modelling these values as a continuous variable. Data in the models were controlled for study centre (Federal University of Viçosa/ University of Navarra), sex, age (years), BMI $\left(\mathrm{kg} / \mathrm{m}^{2}\right)$ or waist circumference $(\mathrm{cm})$, daily energy intake $(\mathrm{MJ} / \mathrm{d})$, physical activity during leisure time (MET-h/week), smoking status and vitamin supplement use. The same procedure was performed in order to analyse the relationships between dietary fibre and vitamin $\mathrm{C}$ intake (from FV) and oxidative stress markers.

Furthermore, we used stepwise multiple regressions ${ }^{(40)}$ to identify the main variability in food items concerning FV consumption of the participants. All statistical analyses were performed with SPSS 15.0 software (SPSS Inc., Chicago, IL, USA) for Windows XP (Microsoft, Redmond, WA, USA). A $P$ value $<0.05$ was considered as statistically significant.

\section{Results}

Anthropometric, clinical and lifestyle characteristics were examined by tertiles of FV consumption (Table 1). Those subjects in the highest tertile were predominately women, with significantly lower values of waist circumference, diastolic blood pressure, glucose, HOMA-IR, TAG, and higher values of HDL-cholesterol and physical activity counts (MET). Participants in the highest tertile of $\mathrm{FV}$ also reported higher vitamin supplement use, compared with those in the lowest tertile $(P<0 \cdot 05)$. 
Moreover, participants who were included in the third tertile of FV consumed more fish and olive oil and had higher intake values for protein, MUFA, dietary fibre, vitamin $\mathrm{C}$ and $\mathrm{Mg}$, compared with those in the lowest tertile of FV consumption (Table 2). In addition, the most commonly consumed FV were apples/pears $\left(R^{2} 0.47\right.$ and $R^{2} 0.40$ for the Brazilian and Spanish study centres, respectively) and tomatoes $\left(R^{2}\right.$ 0.22 and $R^{2} 0.57$ for the Brazilian and Spanish study centres, respectively) in both study locations. Vegetable items accounted for 83 and $100 \%$ of total variability in vegetable consumption for Brazilians and Spaniards, respectively, while fruit items accounted for 99 and $98 \%$ of total variability in fruit consumption (Table 3).

Regarding oxidative stress markers, individuals in the highest tertile of FV consumption had statistically higher TAC values and GPx activity, as well as lower ox-LDL concentrations (Table 4), after adjusting for several covariates. Interestingly, TAC and ox-LDL concentrations were significantly higher and lower, respectively, across tertiles of FV consumption, when FV were analysed separately (Table 4).

Interestingly, TAC and GPx activity values were higher $(P<0.05)$, when the sample was categorised by tertiles of vitamin $C$ consumption, while ox-LDL concentrations were significantly lower, independently of FV consumption (Table 5). In turn, levels of TAC and ox-LDL were also statistically significantly lower and higher, respectively, across tertiles of increasing fibre from FV intake. The concentration of
ox-LDL was found to be independent of FV consumption (Table 5).

Furthermore, secondary analyses were performed in order to evaluate the association between FV consumption and oxidative stress markers. Since FV consumption correlated with other foods/nutrients, the association between FV consumption (as an independent variable) and oxidative stress markers (as outcomes) was analysed using linear regression models, additionally adjusted for dietary fibre, vitamin C, Mg, MUFA or SFA intake as continuous variables. The inverse association between FV intake and these markers remained statistically significant (data not shown).

We also performed additional analyses including fruit juices in the categories of FV consumption, which did not change the outcomes and interpretations. In this context, we separately analysed fruit juice consumption. ox-LDL concentrations were statistically ( $P$ for trend $=0 \cdot 011$ ) lower in subjects included in the third tertile of energy-adjusted fruit juice consumption ( $\geq 170 \mathrm{ml} / \mathrm{d}$ ), compared with those included in the first tertile $(<86 \mathrm{ml} / \mathrm{d})$ in regression models adjusted for study centre, sex, age, BMI, energy intake, smoking habit, physical activity counts and vitamin supplement use. In turn, TAC and GPx activity increased in line with increasing fruit juice consumption, with a tendency towards statistical significance ( $P$ for trend $=0.052$ and 0.072 , respectively), after adjusting for the same covariates.

Table 2. Food and nutrient consumption, according to tertiles $(T)$ of energy-adjusted fruit and vegetable consumption (Mean values with their standard errors, number of participants and percentages, $n$ 246)

\begin{tabular}{|c|c|c|c|c|c|c|c|}
\hline & \multicolumn{6}{|c|}{ Energy-adjusted fruit and vegetable consumption $(\mathrm{g} / \mathrm{d})$} & \multirow[b]{3}{*}{$P^{*}$} \\
\hline & \multicolumn{2}{|c|}{$\mathrm{T} 1(<210)$} & \multicolumn{2}{|c|}{ T2 (210-705) } & \multicolumn{2}{|c|}{ T3 $(\geq 705)$} & \\
\hline & Mean & SE & Mean & SE & Mean & SE & \\
\hline Participants $(n)$ & \multicolumn{2}{|c|}{82} & \multicolumn{2}{|c|}{82} & \multicolumn{2}{|c|}{82} & \\
\hline Energy intake (kJ) & $12351 \cdot 17 \dagger$ & $284 \cdot 512$ & $11012 \cdot 29$ & 351.456 & 10263.35 & $393 \cdot 296$ & $<0.001$ \\
\hline Energy intake (kcal) & $2952 \dagger$ & 68 & 2632 & 84 & 2453 & 94 & $<0.001$ \\
\hline Carbohydrate (\%EI) & 49.4 & 0.8 & $49 \cdot 7 \ddagger$ & 1.0 & $45 \cdot 6$ & 0.8 & 0.002 \\
\hline Dietary fibre $(\mathrm{g} / \mathrm{d})$ & $19.9 \dagger$ & $1 \cdot 2$ & $23 \cdot 1$ & 1.5 & $30 \cdot 4$ & $1 \cdot 3$ & $<0.001$ \\
\hline Protein $(\% \mathrm{EI})$ & $15 \cdot 0 \dagger$ & 0.3 & $15 \cdot 8$ & 0.3 & $17 \cdot 6$ & 0.3 & $<0.001$ \\
\hline Lipids (\%El) & 33.9 & 0.7 & 34.6 & 0.6 & $36 \cdot 3$ & 0.7 & 0.057 \\
\hline MUFA (\%EI) & $7.0 \dagger$ & 0.6 & $9 \cdot 6 \ddagger$ & 0.6 & 14.5 & 0.6 & $<0.001$ \\
\hline PUFA (\%EI) & 5.0 & 0.2 & $5 \cdot 1$ & 0.2 & $5 \cdot 2$ & 0.3 & 0.919 \\
\hline SFA (\%EI) & $11.9 \dagger$ & 0.4 & $9.9 \dagger$ & 0.4 & 8.4 & 0.3 & $<0.001$ \\
\hline Alcohol (g/d) & $13.5 \S$ & $2 \cdot 6$ & $7 \cdot 0$ & $1 \cdot 1$ & 3.5 & 0.7 & 0.002 \\
\hline Cholesterol (mg/d) & $416 \dagger$ & 20 & $297 \ddagger$ & 18 & 258 & 15 & $<0.001$ \\
\hline Cereals $(g / d)$ & 160 & 11.4 & 145 & $10 \cdot 7$ & 160 & $9 \cdot 7$ & 0.360 \\
\hline Legumes $(\mathrm{g} / \mathrm{d})$ & 13.7 & 7.9 & 20.5 & 8.8 & $26 \cdot 5$ & 5.5 & 0.139 \\
\hline Meats $(g / d)$ & $186 \dagger$ & $12 \cdot 0$ & $167 \cdot 78$ & $9 \cdot 0$ & $162 \cdot 7$ & 8.0 & 0.001 \\
\hline Fish $(\mathrm{g} / \mathrm{d})$ & $16 \cdot 2 \dagger$ & $5 \cdot 0$ & $31.6 \ddagger$ & $5 \cdot 0$ & 83.65 & 7.0 & $<0.001$ \\
\hline Nuts $(g / d)$ & $18 \cdot 30$ & $6 \cdot 0$ & 8.9 & $1 \cdot 0$ & $11 \cdot 1$ & 1.0 & 0.631 \\
\hline Dairy products $(\mathrm{g} / \mathrm{d})$ & 287 & 25 & 272 & 17 & 227 & 22 & 0.924 \\
\hline Olive oil (g/d) & $20.9 \S$ & $2 \cdot 5$ & $27 \cdot 8$ & $2 \cdot 8$ & $29 \cdot 0$ & 3.5 & 0.001 \\
\hline Vitamin C $(\mathrm{mg} / \mathrm{d})$ & $88.9 \S$ & $7 \cdot 6$ & $155.9 \ddagger$ & $11 \cdot 0$ & 324 & $15 \cdot 3$ & $<0.001$ \\
\hline $\mathrm{Mg}(\mathrm{mg} / \mathrm{d})$ & $265 \S$ & 13.4 & $285 \ddagger$ & $15 \cdot 0$ & 434 & 17.5 & $<0.001$ \\
\hline
\end{tabular}

$\%$ El, percentage of energy intake.

* $P$ value from one-factor ANOVA test.

† Mean values were significantly different for T1 from those of T3 $(P<0.05$; post hoc Bonferroni test).

$\ddagger$ Mean values were significantly different for T2 from those of T3 $(P<0.05$; post hoc Bonferroni test).

$\S$ Mean values were significantly different for T1 from those of T2 and T3 $(P<0.05$; post hoc Bonferroni test). 


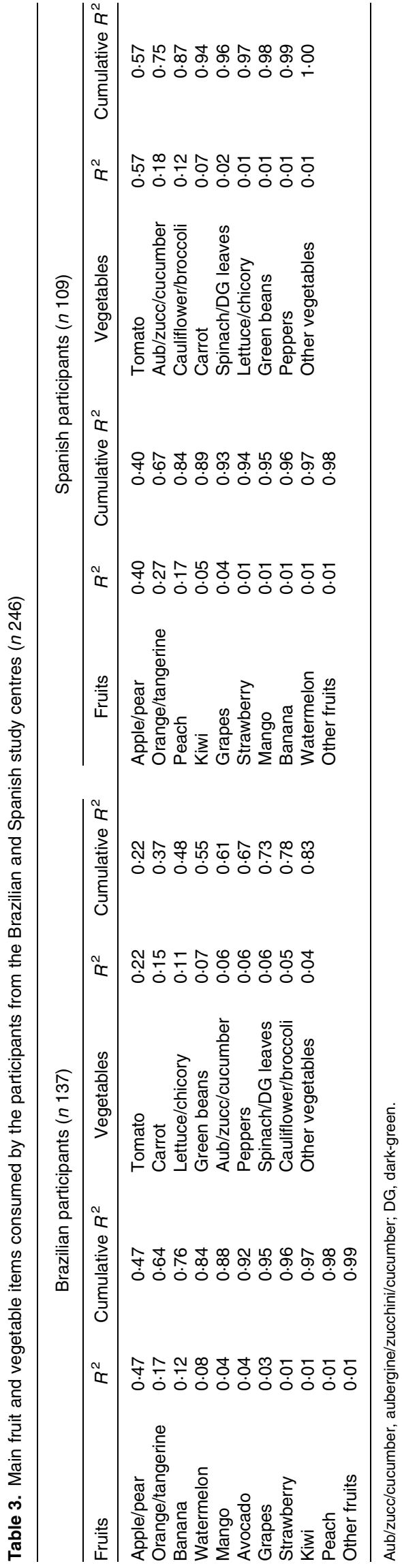

Finally, when we performed linear regression analyses, including separately, waist circumference, diastolic blood pressure, HOMA-IR, HDL-cholesterol or TAG as independent variables, the results followed the same trends and remained statistically significant (data not shown).

\section{Discussion}

In the present study, FV consumption was inversely associated with OX-LDL concentrations and positively associated with plasma TAC and GPx activity in young adults. The present results agree with those obtained in previous intervention studies. For example, a $25 \mathrm{~d}$ intervention study has reported an increment in erythrocyte GPx activity and in the resistance of plasma lipoproteins to oxidation in subjects who consumed a diet rich in FV ( $\geq 600 \mathrm{~g} / \mathrm{d})^{(41)}$. Similarly, higher fruit content in an energy-restricted diet improved antioxidant status in overweight/obese women during weight loss, with a reduction in malondialdehyde:TAC ratio ${ }^{(42)}$. The consumption of tomato and spinach has also enhanced plasma antioxidant capacity and prevented oxidative stress in healthy young adults $^{(43,44)}$. In addition, the resistance to oxidative modification of LDL was enhanced in the $2 \mathrm{~h}$ period after banana meal (400 g) consumption ${ }^{(45)}$.

FV contain vitamins, carotenoids, polyphenols and other still unknown bioactive compounds, which make them a food group with high dietary antioxidant capacity ${ }^{(46,47)}$ and can result in the scavenging of reactive oxygen species produced during lipid peroxidation and other metabolic processes, limiting or preventing oxidative stress. Although the high content of carotenoids and polyphenols (especially the flavonoids) in FV has been associated with the beneficial effect of this food group, the actual contribution of these antioxidant compounds to increases in plasma TAC and reductions in LDL oxidisability is still a matter of debate ${ }^{(48)}$. These opposing views have been attributed to several factors such as the bioavailability of these compounds, the utilisation of different methods to assess ox-LDL concentrations and TAC, the antioxidant defence at non-measurable levels and the effect of food intake per se, including macronutrients, vitamins and other dietary non-antioxidant constituents, all of which could influence the antioxidant effect of $\mathrm{FV}$ on oxidative stress markers ${ }^{(8,48)}$. Furthermore, we found that vitamin $\mathrm{C}$ and fibre from $\mathrm{FV}$ are able to influence oxidative stress markers.

In addition, an anti-inflammatory role of $\mathrm{FV}$ has been proposed, whereby several observational studies have found a reduction in pro-inflammatory markers with increased consumption of these food groups in young and middle-aged $\operatorname{adults}^{(30,49)}$. For example, young adults included in the higher tertile of FV intake $(\geq 660 \mathrm{~g} / \mathrm{d})$ had a lower gene expression of NF-kB1 (p50) as well as relevant cytokines, such as IL-6 and TNF- $\alpha$, in peripheral blood mononuclear cells ${ }^{(30)}$. However, the anti-inflammatory mechanisms related to FV consumption are still unclear.

In the present study, dietary fibre from FV intake was negatively and positively associated with ox-LDL concentrations and TAC, respectively, in healthy young adults. Dietary fibre 
Table 4. Oxidative stress markers with respect to tertiles $(T)^{*}$ of energy-adjusted fruit and vegetable consumptiont

(Mean values with their standard errors)

\begin{tabular}{|c|c|c|c|c|c|c|}
\hline & \multicolumn{2}{|c|}{$\begin{array}{c}\text { TAC } \\
\text { (mmol Trolox) }\end{array}$} & \multicolumn{2}{|c|}{$\begin{array}{c}\text { GPx activity } \\
\text { (nmol/min } \\
\text { per } \mathrm{ml})\end{array}$} & \multicolumn{2}{|c|}{$\begin{array}{l}\text { Ox-LDL } \\
(\mathrm{U} / \mathrm{l})\end{array}$} \\
\hline & Mean & SE & Mean & SE & Mean & SE \\
\hline \multicolumn{7}{|c|}{ Energy-adjusted fruit intake } \\
\hline $\mathrm{T} 1(<84 \mathrm{~g} / \mathrm{d})$ & 1.09 & 0.08 & 595 & 29 & $62 \cdot 2$ & $3 \cdot 1$ \\
\hline T2 $(84-311 \mathrm{~g} / \mathrm{d})$ & $1 \cdot 32$ & 0.08 & 630 & 28 & $35 \cdot 6$ & $3 \cdot 1$ \\
\hline T3 $(\geq 311 \mathrm{~g} / \mathrm{d})$ & 1.43 & $0 \cdot 10$ & 653 & 22 & $38 \cdot 3$ & $3 \cdot 3$ \\
\hline$P$ for trend & \multicolumn{2}{|c|}{0.018} & \multicolumn{2}{|c|}{0.285} & \multicolumn{2}{|c|}{0.015} \\
\hline \multicolumn{7}{|c|}{ Energy-adjusted vegetable intake } \\
\hline $\mathrm{T} 1(<126 \mathrm{~g} / \mathrm{d})$ & 1.06 & 0.08 & 595 & 29 & $62 \cdot 0$ & $3 \cdot 1$ \\
\hline T2 (126-394 g/d) & 1.43 & 0.08 & 604 & 29 & $47 \cdot 7$ & 3.4 \\
\hline T3 $(\geq 394 \mathrm{~g} / \mathrm{d})$ & 1.50 & $0 \cdot 10$ & 671 & 21 & $29 \cdot 9$ & $2 \cdot 6$ \\
\hline$P$ for trend & \multicolumn{2}{|c|}{0.015} & \multicolumn{2}{|c|}{0.069} & \multicolumn{2}{|c|}{$<0.001$} \\
\hline \multicolumn{7}{|c|}{ Energy-adjusted fruit and vegetable intake } \\
\hline $\mathrm{T} 1(<210 \mathrm{~g} / \mathrm{d})$ & 1.08 & 0.07 & 531 & 29 & $61 \cdot 7$ & $3 \cdot 2$ \\
\hline T2 $(210-705 \mathrm{~g} / \mathrm{d})$ & 1.30 & 0.08 & 633 & 27 & $42 \cdot 2$ & $3 \cdot 1$ \\
\hline T3 $(\geq 705 \mathrm{~g} / \mathrm{d})$ & 1.62 & $0 \cdot 10$ & 644 & 23 & $32 \cdot 8$ & 3.4 \\
\hline$P$ for trend & \multicolumn{2}{|c|}{0.019} & \multicolumn{2}{|c|}{0.017} & \multicolumn{2}{|c|}{$<0.001$} \\
\hline
\end{tabular}

TAC, total antioxidant capacity; GPx, glutathione peroxidase; ox-LDL, oxidised LDL.

* T1, $n$ 82; T2, $n$ 82; T3, $n$ 82; GPx activity: T1, $n$ 61; T2, $n$ 62; T3, $n 61$.

$\dagger P$ for trend from the linear regression model, adjusted for study centre (Federal University of Viçosa, Viçosa, Brazi//University of Navarra, Pamplona, Spain), sex (male/female), age (years), BMI $\left(\mathrm{kg} / \mathrm{m}^{2}\right)$, daily energy intake $(\mathrm{MJ} / \mathrm{d})$, smoking habit (never/smoker/former), metabolic equivalent index ( $\mathrm{h} /$ week) and vitamin supplement use (yes/no). Non-normally distributed variables were log-transformed before regression analyses.

from peels, pulps and seeds of FV has the ability to carry antioxidant compounds, such as polyphenols, carotenoids and other minor constituents (i.e. Maillard compounds and trace minerals) through the small and large intestine ${ }^{(50)}$. In this sense, an acute intake of $15 \mathrm{~g}$ of dietary fibre rich in phenolic antioxidants significantly increased plasma TAC in an $8 \mathrm{~h}$ postprandial trial, compared with a control, suggesting that phenolic antioxidants associated with dietary fibre intake might be bioavailable in humans ${ }^{(51)}$. Another interventional study has found a significant reduction in total cholesterol, LDL-cholesterol and TAG concentrations after a supplementation with $7.5 \mathrm{~g} / \mathrm{d}$ of grape antioxidant dietary fibre ${ }^{(52)}$. In rats, dietary fibre from $\mathrm{FV}$ has led to an enhancement of lipid excretion and a reduction in lipid peroxidation ${ }^{(50)}$. These previous findings are in agreement with the present results, indicating a synergic role of fibre and antioxidant compounds from FV intake by improving antioxidant status and preventing lipid oxidation.

In turn, vitamin $\mathrm{C}$ is a recognised antioxidant nutrient, with the ability to scavenge oxygen radicals as well as to regulate collagen synthesis and prostacyclin production, and to maintain NO levels in the vascular wall ${ }^{(53,54)}$. In addition, a decrease in inflammation status has been related to higher vitamin $\mathrm{C}$ intake in middle-aged and elderly people. Vitamin $\mathrm{C}$ was also strongly associated with $\mathrm{FV}$ intake ${ }^{(49,55,56)}$, suggesting the role of this vitamin in the antioxidant and anti-inflammatory effect of FV. In the present study, vitamin $\mathrm{C}$ from FV intake was inversely associated with ox-LDL concentrations and positively associated with plasma TAC and GPx activity. Furthermore, the relationship with plasma TAC was independent of FV consumption, which suggests that vitamin $\mathrm{C}$ intake per se can contribute to the improvement in plasma antioxidant status. In fact, some authors have indicated that vitamin $\mathrm{C}$ contained in FV can significantly affect plasma $\operatorname{TAC}^{(48)}$.

Furthermore, participants included in the third tertile of FV consumption also had a healthier lifestyle, with higher weekly activity counts (MET) and higher vitamin supplement use. In addition, they consumed more recognised beneficial food groups, such as olive oil or fish, or nutrients, such as MUFA, dietary fibre, vitamin $\mathrm{C}$ and $\mathrm{Mg}$, while the intake of SFA, cholesterol, alcohol and meats was reduced across tertiles of FV consumption. However, the inverse associations of FV consumption with oxidative stress markers maintained the trend and the statistical significance after adjustment for MET and vitamin supplement use, as well as for specific dietary factors such as dietary fibre, vitamin C, Mg, MUFA or SFA. In this context, the present findings suggest that additive and synergistic effects of bioactive compounds provided by $\mathrm{FV}$ are responsible for the antioxidant activities of this food group.

Moreover, a positive association between body fat distribution and both pro-inflammatory and oxidative stress markers has been reported ${ }^{(9,13,57,58)}$. Thus, the relationships between FV consumption and oxidative stress and antioxidant capacity could be biased by body fat composition. However, in the present analyses, when we controlled for these potential confounding factors, including BMI or waist circumference as continuous independent variables, the hypothesised associations between FV consumption and oxidative stress markers

Table 5. Oxidative stress markers with respect to tertiles $(T)^{*}$ of energy-adjusted dietary fibre and vitamin $C$ from fruit and vegetable intake

(Mean values with their standard errors)

\begin{tabular}{|c|c|c|c|c|c|c|}
\hline & \multicolumn{2}{|c|}{$\begin{array}{c}\text { TAC } \\
\text { (mmol Trolox) }\end{array}$} & \multicolumn{2}{|c|}{$\begin{array}{c}\text { GPx activity } \\
\text { (nmol/min } \\
\text { per ml) }\end{array}$} & \multicolumn{2}{|c|}{ ox-LDL (U/l) } \\
\hline & Mean & SE & Mean & SE & Mean & SE \\
\hline \multicolumn{7}{|c|}{ Energy-adjusted fibre from fruit and vegetable intake } \\
\hline $\mathrm{T} 1(<6 \mathrm{~g} / \mathrm{d})$ & 1.03 & 0.08 & 521 & 26 & $61 \cdot 3$ & 3.4 \\
\hline T2 $(6-14 \mathrm{~g} / \mathrm{d})$ & 1.38 & $0 \cdot 10$ & 633 & 34 & $40 \cdot 6$ & 3.4 \\
\hline T3 $(\geq 14 \mathrm{~g} / \mathrm{d})$ & 1.58 & 0.08 & 671 & 22 & $29 \cdot 8$ & 2.6 \\
\hline$P$ for trend $\dagger$ & \multicolumn{2}{|c|}{0.009} & \multicolumn{2}{|c|}{0.099} & \multicolumn{2}{|c|}{0.001} \\
\hline$P$ for trend $\ddagger$ & \multicolumn{2}{|c|}{0.215} & \multicolumn{2}{|c|}{0.273} & \multicolumn{2}{|c|}{0.002} \\
\hline \multicolumn{7}{|c|}{ Energy-adjusted vitamin $C$ from fruit and vegetable intake } \\
\hline $\mathrm{T} 1(<60 \mathrm{mg} / \mathrm{d})$ & 1.05 & 0.08 & 537 & 28 & $61 \cdot 7$ & 3.0 \\
\hline T2 $(60-150 \mathrm{mg} / \mathrm{d})$ & 1.34 & 0.8 & 631 & 26 & 44.5 & 3.3 \\
\hline $\mathrm{T} 3(\geq 150 \mathrm{mg} / \mathrm{d})$ & 1.58 & $0 \cdot 10$ & 670 & 25 & $36 \cdot 0$ & 3.4 \\
\hline$P$ for trend $\dagger$ & \multicolumn{2}{|c|}{0.001} & \multicolumn{2}{|c|}{0.001} & \multicolumn{2}{|c|}{0.001} \\
\hline$P$ for trend $\neq$ & \multicolumn{2}{|c|}{0.012} & \multicolumn{2}{|c|}{0.140} & \multicolumn{2}{|c|}{0.194} \\
\hline
\end{tabular}

TAC, total antioxidant capacity; GPx, glutathione peroxidase; ox-LDL, oxidised LDL.

* T1, $n$ 82; T2, $n$ 82; T3, $n$ 82; GPx activity: T1, $n$ 61; T2, $n$ 62; T3, $n 61$.

$\dagger P$ for trend from the linear regression model, adjusted for study centre (Federal University of Viçosa, Viçosa, Brazil/University of Navarra, Pamplona, Spain), sex (male/female), age (years), BMI $\left(\mathrm{kg} / \mathrm{m}^{2}\right)$, daily energy intake $(\mathrm{MJ} / \mathrm{d})$, smoking habit (never/smoker/former), metabolic equivalent index (h/week) and vitamin supplement use (yes/no). Non-normally distributed variables were log-transformed before regression analyses.

$\ddagger P$ for trend from the linear regression model, adjusted for covariates in the previous model plus fruit and vegetable consumption $(\mathrm{g} / \mathrm{d})$. 
maintained the same trend and the statistical significance. This suggests that the effects of FV consumption in the present study were not explained by differences in body fat variables.

Another point relevant for discussion is the joint analyses of data from Brazilian and Spanish young adults, since these two groups have different dietary habits. Interestingly, the food items with the highest contribution to $\mathrm{FV}$ consumption (apple/pear, orange/tangerine and tomato) as well as those that explained the total variability of $\mathrm{FV}$ consumption were the same in both study centres, reinforcing our outcomes. However, vegetable items accounted for less total variability of vegetable consumption for Brazilians, suggesting the involvement of other vegetable items not described in the present study. In addition, the consumption of MUFA from olive oil was higher in the Spanish than in the Brazilian group (16.4 (sE 3.6) v. 5.6 (SE 2.7) \% of energy intake, $P<0.001$ ). This difference was expected since Spain is a Mediterranean country. Despite this difference, the results maintained the trend and significance in regression models adjusted for study centre, olive oil or MUFA intake. Thus, the present findings are independent of this potentially confounding factor.

The present study, however, has certain limitations. First, as the study is cross-sectional, we cannot prove that the reported associations are causal because residual confounding factors may have affected the associations that we observed. However, we controlled for the most important known factors that affect oxidative stress. Second, despite the good correlation between the FFQ and $3 \mathrm{~d}$ record used to assess foodgroup consumption and bioactive compounds in a usual $\operatorname{diet}^{(54,59)}$, the utilisation of different dietary record tools by the Brazilian and Spanish study centres could influence the study results. Third, we were unable to distinguish between the cooking techniques used to store and prepare FV, which might influence the bioavailability of bioactive compounds, including vitamin $C^{(60,61)}$. However, the cross-sectional association between FV consumption and biomarkers has been widely accepted ${ }^{(30,49)}$. Fourth, although the sample size is adequate from the standpoint of initial discovery of relevant associations, further replication with independent and larger samples would be useful for a future translational application to the population level.

In conclusion, the greater consumption of FV was crosssectionally associated with reduced ox-LDL as well as with increased plasma TAC and GPx activity in healthy young adults. This suggests a potential antioxidant-involved mechanism that defends against oxidative stress, or at least favours a beneficial redox balance. In addition, dietary fibre and vitamin $\mathrm{C}$ appear to be implicated in the beneficial relationship of this food group with oxidative stress markers.

\section{Acknowledgements}

This study was supported by the Health Department of the Government of Navarra (22/2007), the 'Línea Especial' about Nutrition, Obesity and Health (University of Navarra LE/97) and the Foundation for Research Support of the State of Minas Gerais (FAPEMIG-CDS 303/06). We wish to thank Blanca E. Martínez de Morentín (physician), Salomé Pérez (nurse) and Verónica Ciaurriz (technician), as well as Elisângela Lessa (nursing assistant) for their excellent technical assistance in the University of Navarra and Federal University of Viçosa, respectively. We also thank the Capes Foundation Ministry of Education of Brazil as well as the Ministry of Education of Spain for supporting the interuniversity cooperation between the Federal University of Viçosa (CAPES/MECD-DGU 109/06) and the University of Navarra (PHB-2005-0119-PC). Finally, we would like to thank Paul W. Miller (lecturer) from the Institute of Modern Languages of the University of Navarra for careful reading of the final version of the manuscript. The authors' contributions were as follows: H. H. M. H. contributed to the design, fieldwork, data collection, analysis and writing of the manuscript; K. B. F. B., A. C. P. V. and B. P. were involved in the design, fieldwork and data collection; J. B., project leader in Brazil, was responsible for the design, financial management and editing of the manuscript; M. A. Z., project co-leader in Spain, was responsible for the design, financial management and editing of the manuscript; J. A. M., project leader in Spain, was responsible for the general coordination, design, financial management and editing of the manuscript. All authors actively participated in the manuscript preparation, as well as read and approved the final version of the manuscript. The authors declare no conflict of interest.

\section{References}

1. Holvoet P, Lee DH, Steffes M, et al. (2008) Association between circulating oxidized low-density lipoprotein and incidence of the metabolic syndrome. JAMA 299, 2287-2293.

2. Meisinger C, Baumert J, Khuseyinova N, et al. (2005) Plasma oxidized low-density lipoprotein, a strong predictor for acute coronary heart disease events in apparently healthy, middle-aged men from the general population. Circulation 112, 651-657.

3. Kwak HK \& Yoon S (2007) Relation of serum total antioxidant status with metabolic risk factors in Korean adults. Nutr Res Pract 1, 335-340.

4. Barbosa KBF, Costa NM, Alfenas RC, et al. (2010) Estresse oxidativo: conceito, implicações e fatores modulatórios (Oxidative stress: concept, implications and modulating factors). Rev Nutr 23, 629-643.

5. Fandos M, Corella D, Guillen M, et al. (2009) Impact of cardiovascular risk factors on oxidative stress and DNA damage in a high risk Mediterranean population. Free Radic Res 43, 1179-1186.

6. Redón J, Oliva MR, Tormos C, et al. (2003) Antioxidant activities and oxidative stress byproducts in human hypertension. Hypertension 41, 1096-1101.

7. Niki E (2010) Assessment of antioxidant capacity in vitro and in vivo. Free Radic Biol Med 49, 503-515.

8. Sies H (2007) Total antioxidant capacity: appraisal of a concept. J Nutr 137, 1493-1495.

9. Chrysohoou C, Panagiotakos DB, Pitsavos C, et al. (2007) The implication of obesity on total antioxidant capacity in apparently healthy men and women: the ATTICA study. Nutr Metab Cardiovasc Dis 17, 590-597.

10. Chrysohoou C, Panagiotakos DB, Pitsavos C, et al. (2007) The association between pre-hypertension status and 
oxidative stress markers related to atherosclerotic disease: the ATTICA study. Atherosclerosis 192, 169-176.

11. Demirbag R, Yilmaz R \& Kocyigit A (2005) Relationship between DNA damage, total antioxidant capacity and coronary artery disease. Mutat Res 570, 197-203.

12. Ishigaki Y, Oka Y \& Katagiri H (2009) Circulating oxidized LDL: a biomarker and a pathogenic factor. Curr Opin Lipidol 20, 363-369.

13. Weinbrenner T, Schroder H, Escurriol V, et al. (2006) Circulating oxidized LDL is associated with increased waist circumference independent of body mass index in men and women. Am J Clin Nutr 83, 30-35.

14. Deshmukh-Taskar PR, O'Neil CE, Nicklas TA, et al. (2009) Dietary patterns associated with metabolic syndrome, sociodemographic and lifestyle factors in young adults: the Bogalusa Heart Study. Public Health Nutr 12, 2493-2503.

15. Dauchet L, Amouyel P, Hercberg S, et al. (2006) Fruit and vegetable consumption and risk of coronary heart disease: a meta-analysis of cohort studies. J Nutr 136, 2588-2593.

16. Lock K, Pomerleau J, Causer L, et al. (2005) The global burden of disease attributable to low consumption of fruit and vegetables: implications for the global strategy on diet. Bull World Health Organ 83, 100-108.

17. Brighenti F, Valtueña S, Pellegrini N, et al. (2005) Total antioxidant capacity of the diet is inversely and independently related to plasma concentration of high-sensitivity C-reactive protein in adult Italian subjects. Br J Nutr 93, 619-625.

18. Puchau B, Zulet MA, de Echavarri AG, et al. (2010) Dietary total antioxidant capacity is negatively associated with some metabolic syndrome features in healthy young adults. Nutrition 26, 534-541.

19. NEPA-UNICAMP (2006) Tabela Brasileira de Composição de Alimentos (TACO) Versão II (Brazilian Table of Food Composition (TACO) Version II). http://www.unicamp.br/ nepa/taco/contar/taco_versao2.pdf

20. Philippi ST (2002) Tabela de composição de alimentos: Suporte para decisão nutricional (Table of Food Composition: Support for Nutritional Decision), 2nd ed. São Paulo: Editora Metha.

21. Fernández-Ballart JD, Pinol JL, Zazpe I, et al. (2010) Relative validity of a semi-quantitative food-frequency questionnaire in an elderly Mediterranean population of Spain. Br J Nutr 103, 1808-1816.

22. Mataix J (2009) Tabla de composición de alimentos (Food Composition Table), 5th ed. Granada: Universidad de Granada.

23. Moreiras O, Carbajal A, Cabrera L, et al. (2006) Tabla de composición de alimentos (Food Composition Table), 10th ed. Madrid: Ediciones Pirámide.

24. IOM (2002) Institute of Medicine. Dietary Reference Intakes for Energy, Carbohydrate, Fiber, Fat, Fatty Acids, Cholesterol, Protein, and Amino acids (Macronutrients). Washington, DC: The National Academies Press.

25. Mendez MA, Popkin BM, Buckland G, et al. (2011) Alternative methods of accounting for underreporting and overreporting when measuring dietary intake-obesity relations. Am J Epidemiol 173, 448-458.

26. Hermsdorff HHM, Zulet MA, Puchau B, et al. (2009) Association of retinol-binding protein- 4 with dietary selenium intake and other lifestyle features in young healthy women. Nutrition 25, 392-399.

27. Pérez S, Parra MD, Martínez de Morentin B, et al. (2005) Evaluación de la variabilidad intraindividual de la medida de composición corporal mediante bioimpedancia en voluntarias sanas y su relación con el índice de masa corporal y el pliegue tricipital (Evaluation of intrasubject variability in the measurement of body composition using electrical bioimpedance in healthy volunteers and body mass index and triceps skinfold measurement). Enferm Clin 15, 307-314.

28. WHO (1998) Programme of Nutrition, Family and Reproductive Health. Obesity. Preventing and Managing the Global Epidemic. Report of a WHO Consultation on Obesity. Geneva: World Health Organization.

29. Whitworth JA \& Chalmers J (2004) World health organisation-international society of hypertension (WHO/ISH) hypertension guidelines. Clin Exp Hypertens 26, 747-752.

30. Hermsdorff HHM, Zulet MA, Puchau B, et al. (2010) Fruit and vegetable consumption and proinflammatory gene expression from peripheral blood mononuclear cells in young adults: a translational study. Nutr Metab (Lond) 7, 42.

31. Friedewald WT, Levy RI \& Fredrickson DS (1972) Estimation of the concentration of low-density lipoprotein cholesterol in plasma, without use of the preparative ultracentrifuge. Clin Chem 18, 499-502.

32. Matthews DR, Hosker JP, Rudenski AS, et al. (1985) Homeostasis model assessment: insulin resistance and beta-cell function from fasting plasma glucose and insulin concentrations in man. Diabetologia 28, 412-419.

33. Holvoet P, Donck J, Landeloos M, et al. (1996) Correlation between oxidized low density lipoproteins and von Willebrand factor in chronic renal failure. Thromb Haemost 76, 663-669.

34. Holvoet P, Macy E, Landeloos M, et al. (2006) Analytical performance and diagnostic accuracy of immunometric assays for the measurement of circulating oxidized LDL. Clin Chem 52, 760-764.

35. Miller NJ, Rice-Evans C, Davies MJ, et al. (1993) A novel method for measuring antioxidant capacity and its application to monitoring the antioxidant status in premature neonates. Clin Sci (Lond) 84, 407-412.

36. Miller NJ \& Rice-Evans CA (1997) Factors influencing the antioxidant activity determined by the $\mathrm{ABTS}^{*+}$ radical cation assay. Free Radic Res 26, 195-199.

37. Ceballos-Picot I, Trivier JM, Nicole A, et al. (1992) Agecorrelated modifications of copper-zinc superoxide dismutase and glutathione-related enzyme activities in human erythrocytes. Clin Chem 38, 66-70.

38. Ching PL, Willett WC, Rimm EB, et al. (1996) Activity level and risk of overweight in male health professionals. Am J Public Health 86, 25-30.

39. Martínez-González MA, López-Fontana C, Varo JJ, et al. (2005) Validation of the Spanish version of the physical activity questionnaire used in the Nurses' Health Study and the Health Professionals' Follow-up Study. Public Health Nutr 8, 920-927.

40. Willett WC (1998) Nutritional Epidemiology, 2nd ed. New York, NY: Oxford University Press.

41. Dragsted LO, Pedersen A, Hermetter A, et al. (2004) The 6-a-day study: effects of fruit and vegetables on markers of oxidative stress and antioxidative defense in healthy nonsmokers. Am J Clin Nutr 79, 1060-1072.

42. Crujeiras AB, Parra MD, Rodriguez MC, et al. (2006) A role for fruit content in energy-restricted diets in improving antioxidant status in obese women during weight loss. Nutrition 22, 593-599.

43. Porrini M, Riso P \& Oriani G (2002) Spinach and tomato consumption increases lymphocyte DNA resistance to oxidative stress but this is not related to cell carotenoid concentrations. Eur J Nutr 41, 95-100.

44. Riso P, Visioli F, Grande S, et al. (2006) Effect of a tomatobased drink on markers of inflammation, immunomodulation, and oxidative stress. J Agric Food Chem 54, 2563-2566. 
45. Yin X, Quan J \& Kanazawa T (2008) Banana prevents plasma oxidative stress in healthy individuals. Plant Foods Hum Nutr 63, 71-76.

46. Hermsdorff HH, Zulet MA \& Martinez JA (2011) The implication of unknown bioactive compounds and cooking techniques in relations between the variety in fruit and vegetable intake and inflammation. Am J Clin Nutr $\mathbf{9 3}$, 1384 .

47. Martínez-González MA \& Lamuela-Raventos RM (2009) The unparalleled benefits of fruit. Br J Nutr 102, 947-948.

48. Lolito SB \& Frei B (2006) Consumption of flavonoid-rich foods and increased plasma antioxidant capacity in humans: cause, consequence, or epiphenomenon? Free Radic Biol Med 41, 1727-1746.

49. Oliveira A, Rodriguez-Artalejo F \& Lopes C (2009) The association of fruits, vegetables, antioxidant vitamins and fibre intake with high-sensitivity C-reactive protein: sex and body mass index interactions. Eur J Clin Nutr $\mathbf{6 3}$, $1345-1352$.

50. Saura-Calixto F (2010) Dietary fiber as a carrier of dietary antioxidants: an essential physiological function. J Agric Food Chem 59, 43-49.

51. Pérez-Jiménez J, Serrano J, Tabernero M, et al. (2009) Bioavailability of phenolic antioxidants associated with dietary fiber: plasma antioxidant capacity after acute and long-term intake in humans. Plant Foods Hum Nutr 64, $102-107$.

52. Pérez-Jiménez J, Serrano J, Tabernero M, et al. (2008) Effects of grape antioxidant dietary fiber in cardiovascular disease risk factors. Nutrition 24, 646-653.

53. Helmersson J, Arnlov J, Larsson A, et al. (2009) Low dietary intake of beta-carotene, alpha-tocopherol and ascorbic acid is associated with increased inflammatory and oxidative stress status in a Swedish cohort. Br J Nutr 101, 1775-1782.

54. Talegawkar SA, Beretta G, Yeum KJ, et al. (2009) Total antioxidant performance is associated with diet and serum antioxidants in participants of the diet and physical activity substudy of the Jackson Heart Study. J Nutr 139, 1964-1971.

55. Holt EM, Steffen LM, Moran A, et al. (2009) Fruit and vegetable consumption and its relation to markers of inflammation and oxidative stress in adolescents. J Am Diet Assoc 109, 414-421.

56. Wannamethee SG, Lowe GD, Rumley A, et al. (2006) Associations of vitamin $\mathrm{C}$ status, fruit and vegetable intakes, and markers of inflammation and hemostasis. Am J Clin Nutr 83, 567-574.

57. Hermsdorff HHM, Puchau B, Zulet MA, et al. (2010) Association of body fat distribution with proinflammatory gene expression in peripheral blood mononuclear cells from young adult subjects. OMICS 14, 297-307.

58. Hermsdorff HHM, Zulet MA, Puchau B, et al. (2011) Central adiposity rather than total adiposity measurements are specifically involved in the inflammatory status from healthy young adults. Inflammation 34, 161-170.

59. Puchau B, Zulet MA, de Echavarri AG, et al. (2009) Dietary total antioxidant capacity: a novel indicator of diet quality in healthy young adults. J Am Coll Nutr 28, 648-656.

60. Danesi F \& Bordoni A (2008) Effect of home freezing and Italian style of cooking on antioxidant activity of edible vegetables. J Food Sci 73, H109-H112.

61. Miglio C, Chiavaro E, Visconti A, et al. (2008) Effects of different cooking methods on nutritional and physicochemical characteristics of selected vegetables. J Agric Food Chem 56, 139-147. 